\title{
Configurações
}

Revista de sociologia

\section{Vigilantes eletrônicos no Rio de Janeiro: agenciamentos sociotécnicos e pesquisa em tecnologia}

Electronic surveillants in Rio de Janeiro: sociotechnical agencements and research in technology

Surveillants eléctroniques à Rio de Janeiro : agencements socio-techniques et recherche en technologie

\section{Bruno de Vasconcelos Cardoso}

\section{OpenEdition}

Journals

\section{Edição electrónica}

URL: http://journals.openedition.org/configuracoes/820

DOI: $10.4000 /$ configuracoes.820

ISSN: $2182-7419$

\section{Editora}

Centro de Investigação em Ciências Sociais

Edição impressa

Data de publição: 5 Fevereiro 2011

Paginação: 97-108

ISSN: 1646-5075

\section{Refêrencia eletrónica}

Bruno de Vasconcelos Cardoso, « Vigilantes eletrônicos no Rio de Janeiro: agenciamentos sociotécnicos e pesquisa em tecnologia », Configurações [Online], 8 | 2011, posto online no dia 21 fevereiro 2013, consultado o 30 abril 2019. URL : http://journals.openedition.org/configuracoes/820 ; DOI : 10.4000/configuracoes.820

Este documento foi criado de forma automática no dia 30 Abril 2019.

(c) CICS 


\section{Vigilantes eletrônicos no Rio de Janeiro: agenciamentos sociotécnicos e pesquisa em tecnologia}

Electronic surveillants in Rio de Janeiro: sociotechnical agencements and research in technology

Surveillants eléctroniques à Rio de Janeiro : agencements socio-techniques et recherche en technologie

Bruno de Vasconcelos Cardoso

\section{Introdução}

1 Ao longo dos últimos vinte anos vem se desenvolvendo um importante campo de estudos dedicado ao crescente uso de tecnologias para fins de controle social e vigilância ( surveillance studies). Parte considerável dessa bibliografia fala da emergência de uma sociedade hipervigiada, onde câmeras, bancos de dados e uma série de objetos tecnológicos trabalhariam de forma integrada na produção e análise constante de informações, a fim de classificar e categorizar a população, para fins de controle ${ }^{1}$.

2 No presente artigo, com base em trabalho etnográfico realizado em salas de controle da polícia do Rio de Janeiro, busco problematizar tal idéia, atentando para as incontornáveis diferenças entre os discursos sobre as capacidades da tecnologia e as dificuldades e desafios trazidos por seu funcionamento prático². Identifico como principal pilar de sustentação de abordagens que apontam para uma hipervigilância tecnológica, a negligência em relação à grande complexidade ${ }^{3}$ envolvida nas relações entre homens e máquinas necessárias ao funcionamento da tecnologia. Nesse sentido, a obra de autores da chamada teoria do ator-rede, como Michel Callon, Bruno Latour, John Law e Madeleine Akrich, se mostra central, ao apontar para os constantes movimentos de tradução entre 
diferentes linguagens ${ }^{4}$, e de mediação entre materialidades heterogêneas, que constituem a tecnologia.

3 Dessa forma, concentro-me na figura do vigilante eletrônico, híbrido ${ }^{5}$ homem-máquina surgido com o videomonitoramento, para discutir a constituição tanto da tecnologia quanto daqueles que devem trabalhar constantemente com ela.

\section{Pesquisando a videovigilância no Rio de Janeiro}

Em maio de 2008, no intuito da realização de uma tese de doutoramento (Cardoso, 2010), comecei a pesquisar o Centro de Comando e Controle (CCC) da Polícia Militar, uma sala no 13. ${ }^{\circ}$ andar da torre da Central do Brasil ${ }^{6}$, onde as imagens de todas as câmeras operadas pela polícia no Rio de Janeiro são reunidas. Nesse espaço, policiais passam o dia de trabalho diante de um fluxo contínuo de imagens, tendo como função principal supervisionar o trabalho realizado pelos operadores locais de câmeras, lotados nos batalhões da Polícia Militar (BPM) espalhados pelo estado (além da capital, também nos municípios de Niterói, Alcântara, Nova Iguaçu, Duque de Caxias e Queimados). $O$ auxílio ao trabalho destes operadores locais também era citado como uma das funções ali desempenhadas. Lá se localizava o escritório do Supervisor de Comando e Controle, o Coronel $^{7}$, como todos o chamavam, que se revelou uma figura fundamental na pesquisa, como informante e também como mediador. Até agosto, foi no CCC que o trabalho etnográfico foi realizado. Sentava-me atrás de todos os operadores, numa bancada superior, junto com alguns outros policiais que realizavam outra função (rádio e telefone), e os via o tempo todo, por detrás, sem ser visto por eles na maior parte do tempo. Sabiam que eu estava ali, pois logo que eu chegava a minha presença era notada e alvo de comentários jocosos (sempre me "acusavam" de jornalista e de "X9")". Apesar do teor das brincadeiras, nunca senti animosidade: minha presença não parecia intimidatória, ainda mais se comparada com a do Coronel, bem ao centro da sala, num escritório de vidro.

5 A partir do final de agosto (até o fim do ano), passei a freqüentar a sala de monitoramento do 19. Batalhão de Polícia Militar (19. BPM), e acompanhar de perto o trabalho realizado pelos operadores das câmeras no bairro pioneiro do monitoramento, Copacabana, e onde, segundo o coronel, teria havido uma redução mais drástica da criminalidade. Copacabana era sempre apontada por meus interlocutores no CCC como um exemplo positivo do funcionamento do sistema ${ }^{9}$. Pude acompanhar atentamente o trabalho, sentando-me na mesma bancada que os operadores. Eu os observava, mas era também constantemente observado. A minha observação era forçosamente participante, controlada, atuante. 0 efetivo dos monitoradores era formado por ex-policiais e ex-bombeiros aposentados ou reformados, todos eles com idade avançada, entre sessenta e oitenta anos. Essa questão é fundamental para entender a realização do trabalho de videovigilância, pois tem relação direta com seus dois principais aspectos, o olhar e a interação com os computadores.

\section{Videovigilância em outros países}

6 É preciso destacar que, ao longo desse período, acompanhei um projeto de segurança pública em implantação, cujo pouco tempo de funcionamento poderia perfeitamente maximizar alguns de seus problemas ou virtudes, assim como não permitir que outros se 
consolidassem. Entretanto, o sistema de videovigilância dos espaços públicos vem sendo testado há mais tempo em outros países e metrópoles, o que acaba resultando na constituição de um considerável corpus bibliográfico sobre o assunto - tanto textos acadêmicos ou jornalísticos quanto relatórios avaliativos. Especialmente na Grã-Bretanha, onde há o maior número de câmeras nas ruas (a CCTV - Closed Circuit Television), operando há mais tempo, já que há pelo menos uma década e meia o assunto vem recebendo status prioritário do Home Office. E há, em parte dessa bibliografia, pontos em comum com o que observei tanto no CCC quanto no 19. BPM, o que me leva a crer que o sistema de videovigilância no Rio de Janeiro, por mais que conserve peculiaridades bastante brasileiras - e muito deva à personalidade e atitudes daqueles que nele trabalham -, guarda elementos em comum com padrões internacionais, estabelecidos em contextos bastante diversos.

7 Entretanto, são consideráveis as diferenças que separam as conjunções do videomonitoramento em cada país ou região ${ }^{10}$. Na Grã-Bretanha, como explicam McCahill, Norris e Wood (2004: 121),

não havia simplesmente nenhuma disposição legal para a proteção da vida privada, nenhuma base legal ou constitucional que pudesse tanto inibir desenvolvedores do sistema em potencial quanto dar aos detratores da CCTV uma arma para desafiar sua implantação (ver Sharpe, 1989; Taylor, 2002).

8 Na França, apesar do acelerado desenvolvimento dos sistemas de câmeras no espaço público, este se deu de forma bastante diferente do britânico. Para a implantação inicial do sistema, foi necessária a promulgação de uma lei em janeiro de $1995^{11}$, em vigor há dezessete anos, onde era regulamentada a construção de arquivos informatizados sobre os indivíduos (que dera origem ao CNIL, Comission nationale de l'informatique et des libertés ${ }^{12}$ ). E seguindo a tradição burocrática francesa oposta à inglesa, a vigilância eletrônica nos espaços públicos é alvo de regulamentação restritiva, visando a proteção das "liberdades individuais", dentre as quais destaco que "toda pessoa filmada tem o direito de interrogar o responsável pelo sistema ${ }^{13}$ para saber se é fichada, e caso seja, de saber em que arquivo".

9 Estudos comparativos internacionais (McCahill, Norris e Wood, 2004; Hempel e Töpfer, 2002) apontam uma diferença significativa entre países onde, assim como no Reino Unido, o desenvolvimento da videovigilância do espaço público foi rápido e inconteste, como Hungria (Molnar, 2003), República Tcheca e China (Walton, 2001), e aqueles onde não foi tomada, ao menos de início, como uma política oficial de segurança, como Áustria, Alemanha, Dinamarca e Suécia. As explicações apontam para uma relação com a existência ou não de legislação de proteção de dados individuais, direitos humanos e regulamentação do espaço público. Os Estados Unidos constituem um caso especial em que, apesar do grande mercado e da larga utilização de câmeras de segurança, em um primeiro momento não houve uma apropriação destas como instrumento policial: a vigilância é, em sua maioria, esmagadora, privada, o que também é significativo da estrutura sociopolítica norte-americana.

\section{Pesquisando a videovigilância: distância e proximidade}

10 Apesar destas diferenças entre contextos particulares, dentro da extensa bibliografia produzida sobre o tema, podemos observar que, em sua maior parte, a videovigilância continua sendo tratada sob os prismas do controle e da disciplina panopcista, retomando 
essencialmente Bentham (2000), Orwell (1979) e Foucault (2003). O surgimento de sistemas de câmeras de vigilância foi tratado como a emergência de uma "sociedade da vigilância" (Lyon, 1993, 1994; Fyfe e Bannister, 1996; Reeve, 1998). Isso se deve em muito à forma como grande parte desses trabalhos foi produzida, distante das realizações práticas do videomonitoramento, em elucubrações teóricas invariavelmente baseadas na crença no "poder supremo" da tecnologia, e nos discursos daqueles que promovem tais políticas de segurança. A sobredeterminação técnica ${ }^{14}$ borra as fronteiras entre realidade e ficção científica, entre modelos teóricos e realizações práticas e entre promessas e concretizações. Os textos que apontam um pretenso fim da privacidade (Whitaker, 1999; Sewell e Barker, 2001), que teria sido golpeada mortalmente pela proliferação das câmeras de vigilância no espaço público citadino, também se baseiam na premissa de um supercontrole sobre a vida individual, mantendo considerável distância das reais possibilidades do sistema técnico em questão, além de uma idéia bastante peculiar e simplista da própria privacidade. Como ressalta Cameron (2004: 137), a propósito da alta tecnologia de vigilância:

Apesar do marketing hype das firmas de segurança, existem problemas técnicos ainda maiores para identificar de maneira confiável pessoas em condições de campo, que estão se movendo e não cooperando ativamente com a captura em vídeo pelas câmeras. Isso se deve à necessidade de maior luminosidade, de um ângulo específico da face para a câmera, captura em vídeo de alta resolução para permitir a um algoritmo facial ser alcançado.

11 Já as pesquisas baseadas no acompanhamento do trabalho prático de monitoramento por câmeras, tendem a se distanciar dessas visões mais radicais e alarmistas, e também a desconfiar das propaladas "virtudes milagreiras" da videovigilância para a segurança pública. Exemplos importantes são os estudos etnográficos de Smith $(2004,2007)$ e Cardoso (2010), ou a análise do "sistema sociotécnico" realizada por Keval e Sasse (2006), cientistas da computação que trazem uma visão bastante diferente da questão. 0 mesmo ocorre com as avaliações acadêmicas (Heilmann e Mornet, 2001; Le Goff e Fonteneau, 2008) e oficiais, inclusive a mais importante delas, realizada pelo próprio Home Office britânico (Gill e Spriggs, 2005), cujo forte teor das críticas não deixa de ser surpreendente se tivermos em conta que partem do principal promotor da CCTV.

12 A simples observação do trabalho de videomonitoramento evidencia que não são apenas questões técnicas que impedem a vigilância ao estilo do Big Brother - menos o ditador do que o programa televisivo -, esta só sendo imaginável - mesmo se de difícil execução - em contextos de reduzidíssimo contingente populacional, no qual as redes sociais fossem "multiplex"15 (Mitchell, 1969), ou de malhas estreitas (Bott, 1976), com maior possibilidade da construção de um discurso coerente sobre o outro observado através das câmeras. Parece evidente, o porteiro do meu prédio tem maior possibilidade de me "vigiar" do que o operador de câmeras do bairro onde moro - o que não quer dizer que possa efetivamente me controlar, apenas, no máximo, para além das informações de que dispõe sem a necessidade de câmeras, ver o que faço no elevador e corredores do edifício. Para os operadores de câmeras que vigiam à distância desconhecidos, a possibilidade de que a observação diária possa constituir um banco de dados sobre alguns desses observados é inegavelmente remota. Como lembra Koskela (2003: 304),

O vídeo [...] não é o melhor equipamento possível para categorização. Ao contrário

da prisão panóptica, no espaço urbano, a maioria daqueles que são vistos permanecem não identificados e, portanto, não podem ser ligados a informações que poderiam ser utilizadas para a codificação e a classificação. 
13 Nas situações de monitoramento que tive a oportunidade de acompanhar - uma experiência essencialmente metropolitana -, a observação recaía na maioria esmagadora do tempo sobre anônimos descontextualizados e durante curtos períodos, enquanto se mantinham no campo de visão da câmera. Esse fator impossibilitava a constituição de narrativas minimamente estruturadas, capazes de despertar o interesse dos próprios vigilantes. Na maior parte do tempo, a fragmentação radical das imagens as tornava dificilmente interessantes tanto para o combate ao crime em geral quanto para um possível excesso de atenção sobre a vida pessoal dos observados, o que enfraquece as maiores paranoias em torno do supercontrole estatal sobre os indivíduos e também de um avanço predatório sobre a vida íntima e privada das pessoas. Como lembra Lianos (2001, 2003), a "liberdade interna" é provavelmente maior hoje que durante praticamente a totalidade do século anterior: o novo controle social ${ }^{16}$ não se importaria com a intimidade dos controlados, apenas com o respeito impessoal a regras desnormatizadas. Pelo que pude constatar através da videovigilância, mesmo que esse controle sobre a vida íntima das pessoas fosse um objetivo, definitivamente não seria através de câmeras no espaço púbico que ele seria alcançado. No máximo, renderia alguns flagrantes esparsos que, longe de controlar, serviriam apenas para divertir os operadores.

\section{Máquinas e humanos: interações entre mão de obra e estrutura tecnológica}

Não são, contudo, quesitos relativos às medições de eficiência do videomonitoramento que evidenciam a inadequação das teorias que pregam uma "sociedade da vigilância" ou o "fim da privacidade" para falar da videovigilância. A simples observação do trabalho dos operadores de câmeras basta para lembrar-nos que estamos diante de um serviço executado por humanos, com as habituais limitações e estratégias de "contra-trabalho". Mesmo que a estrutura técnica oferecida proporcionasse uma vigilância controladora total, seria necessário um corpo de trabalhadores extremamente treinados e preparados, desempenhando o serviço com afinco e dedicação absolutos e atenção redobrada. Situação muito distante da encontrada por todos que frequentaram as salas de monitoramento, tendo em vista o que Gavin Smith chamou de fator tédio (boredom factor) (2004: 388):

o boredom factor surge, principalmente, da visualização de horas de monótonas e rotineiras imagens televisivas, sem que nada aconteça. [...] Como se pode bem imaginar, este é um tempo muito longo para ficar sentado olhando essencialmente nada.

Aliada ao tédio, a baixa remuneração dos operadores de câmeras contribui ainda mais para o desestímulo presenciado - não apenas por mim, mas também por Smith $(2004,2007)$-, ainda mais se a tomarmos em conjunto com a preparação insuficiente para aquele serviço. Pois também essencial - e poucas vezes levado em conta - é que para um monitoramento mais eficiente, seria necessária uma mão de obra mais qualificada $\mathrm{e}$ - eis o maior dos problemas -, bem melhor remunerada. Exemplar nesse sentido é a frase dita por um policial do CCC, indicando simultaneamente sua desqualificação para qualquer serviço, a maneira relapsa com que desempenha seu trabalho e a sua falta de ambição diante da remuneração baixa que recebe: "eu não sei fazer nada direito aí fora, ganhando mil reais pra ficar aqui sentado acho que to ganhando benzão!" ${ }^{17}$. 
16 Deve-se igualmente destacar que os sistemas de videovigilância representam consideráveis gastos financeiros, incluindo a infra-estrutura, a manutenção e os custos com pessoal, o monitoramento propriamente dito. Em toda a Grã-Bretanha, por exemplo, estima-se que entre 1994 e 2004 tenham sido gastos entre quatro e cinco bilhões de libras esterlinas em sistemas de $\mathrm{CCTV}^{18}$, apenas em estrutura e manutenção, dentre os quais mais de 250 milhões ${ }^{19}$ de dinheiro público (McCahill, Norris e Wood, 2004), representando mais de três quartos do orçamento destinado à prevenção criminal (Welsh e Farrington, 2004). E, como já foi percebido nos contextos no qual foram instalados, os sistemas de videovigilância tendem a se "retroalimentar": "uma vez o sistema estabelecido a demanda tem tendência a crescer no interior da organização em questão" (Le Goff e Fonteneau, 2008: 38). Diante desse panorama de custos elevados em investimento técnico (e na manutenção destes), indispensáveis para instalação e funcionamento mínimo do sistema, somente nas despesas com pessoal é possível cortar gastos. E é realmente com a mão de obra, tratada como um elemento de menor importância no monitoramento por câmeras, que a economia foi feita. A ausência de regras trabalhistas - os operadores dos BPM eram tratados oficialmente como "voluntários", "nem contrato assinado tinham", como enfatizou um deles - e a situação de dificuldade financeira que muitos atravessavam, numa idade já avançada, fazia com que o nível de qualificação e remuneração fosse ainda mais baixo. Recebiam "auxílio", e não salário, enquanto os policiais que trabalhavam no CCC continuavam recebendo apenas seu soldo habitual, não gerando nenhum gasto adicional para a Polícia Militar.

17 E, bastante significativo dessa "economia com pessoal", os encarregados diretos pela videovigilância mostravam desconhecimento quase total do instrumento de trabalho, o computador. Os conhecimentos de informática eram parcos, mesmo entre os policiais, mais jovens que os operadores do 19. BPM, não habituados à linguagem e recursos dos computadores, objeto com o qual interagiam diretamente todo o tempo em que estavam ali. Comandos e ações que para grande parte dos jovens do Rio de Janeiro são simples e banais ganham ares de grande desafio para os operadores, tomando-lhes muito mais tempo do que deveriam e fazendo o trabalho tornar-se muito menos dinâmico do que seria preciso. E diante de tal falta de intimidade, pouquíssimo auxílio e nenhuma formação específica complementar eram conferidos a eles.

18 Venho tratando o vigilante eletrônico (Cardoso, 2010) como um agenciamento sociotécnico (Callon, 2003), ou seja, como uma junção criadora de elementos humanos e maquínicos, que associados criam algo diferente do que a soma de suas partes. Todos esses elementos atuam como mediadores (Latour, 1994, 2007) na constituição de uma grande rede sociotécnica, em constante transformação: o sistema de videovigilância. A relação dos humanos com os mediadores técnicos ${ }^{20}$ - agenciamento constituinte dos vigilantes eletrônicos - é negligenciada pelos formuladores e apologistas do videomonitoramento, assim como pelos inimigos da videovigilância, portadores de discursos alarmistas em relação a tendências totalitaristas ou ameaças à privacidade e intimidade trazidas pelas câmeras. Os elementos que a formam - homens e máquinas - são tomados em separado, cada um guardando suas virtudes. A experiência prévia de atuação nas ruas e o olhar maldoso ${ }^{21}$ dos operadores são lembrados pelos "voluntários" do 19. BPM, pelos policiais do CCC e pelo supervisor (representando os "discursos oficiais" da Polícia Militar e da Secretaria de Segurança Pública) como valorosas armas no desempenho do monitoramento. No entanto, sem os objetos técnicos, esse olhar maldoso nada veria além das paredes da sala e da movimentação dos colegas e teria que guardar as imagens apenas 
na memória (humana). Já as câmeras e o aparato tecnológico que as sustentam são louvados pelas amplas possibilidades de deslocamento espacial e de eternização do visualizado, fatores responsáveis pela especificidade da vigilância eletrônica. Contudo, estes apenas captam informações, que codificam e transmitem em linguagem numérica, cuja recomposição em imagens e em cenas depende dos mediadores humanos, seu olhar e sua capacidade interpretativa.

Seguindo o raciocínio oficial, a falta de conhecimento dos princípios elementares da informática seria compensada pela experiência de trabalho daquelas pessoas, pela malícia e paciência de uma observação mais qualificada, de um olho que aprendeu a ver com o tempo, mesmo se através de diferentes meios. Entretanto, o saber que aqueles "voluntários" carregavam, adquirido através de experiências acumuladas ao longo de toda uma vida profissional, apesar de valioso e de maneira alguma negligenciável, era intraduzível para a linguagem das câmeras, da tecnologia, dos híbridos homem-máquina que constituíam. O olhar deles era inadaptável àquele modo técnico de olhar. $\mathrm{Na}$ elaboração e implementação da política de vigilância eletrônica, a revolução dos meios de comunicação é minimizada, assim como é desconsiderada a especificidade do olhar que criam. Fator que ganha ainda mais interesse quando confrontado com a supervalorização desses mesmos meios técnicos, onipresente tanto nos discursos quanto nos mitos sobre o sistema de monitoramento por câmeras, assim como em sua própria concepção. Minimizar ou supervalorizar são duas faces da mesma moeda: ambas as posturas ignoram a necessidade intrínseca da interação sujeito-objeto, para a existência objetiva tanto de um quanto do outro. $O$ vigilante não existe sem a câmera e esta não tem nenhuma função sem o seu olhar. Nem homem nem meio técnico existem em seu estado puro na vigilância eletrônica.

\section{Conclusão}

20 A relação (negligenciada) entre os dois tipos de elementos - pessoas e tecnologia - é o âmago da videovigilância, mas também sua parte mais problemática e menos levada em conta. Sendo mantida na penumbra a relação entre os elementos humanos e maquínicos, é possível, estratégica e discursivamente, que as vantagens do sistema sejam enaltecidas e ressaltadas, enquanto suas fraquezas são mascaradas. Tem-se ao mesmo tempo a capacidade trazida pela tecnologia de desterritorialização e multiplicação do olhar ampliado, e a experiência social e malícia humana, capaz de perceber e reconhecer comportamentos suspeitos.

21 No entanto, ambos são pensados de forma independente: a tecnologia apenas desterritorializaria e multiplicaria a percepção qualificada dos operadores de câmera; por outro lado, essas pessoas apenas viabilizariam o trabalho poderoso e qualificado do sistema tecnológico. Mão de obra e estrutura técnica são tratados como elementos purificados, embora a videovigilância seja constituída pela criação de um híbrido, de um agenciamento sociotécnico. $\mathrm{E}$, mais do que isso, em torno dessa purificação são construídas promessas superestimadas, são elaborados planejamentos e postos em prática dispendiosas políticas públicas. Assim como são criados "pesadelos" e distopias totalitárias.

No caso que pesquisei, a questão da sobredeterminação técnica surgiu com bastante força, coadunando-se a traços bastante característicos dos universos do trabalho e da polícia no Brasil. Entretanto, não creio que diga respeito apenas a desafios e problemas locais da 
videovigilância, nem mesmo que se resuma ao âmbito da videovigilância. Os problemas revelados pelo contexto estudado concernem à tecnologia como um todo e, mais especificamente, a pesquisa e o estudo em tecnologia, a importância do método de pesquisa etnográfico e, mais ainda, a centralidade das conexões, interações, agenciamentos para compreender os desafios, situações e identidades (profissionais ou não) que vêm surgindo no contexto sociotécnico contemporâneo. Apenas através do acompanhamento aproximado desses agenciamentos é possível escapar das promessas, ameaças e profecias que povoam os discursos (e as práticas) relativos à tecnologia.

\section{BIBLIOGRAPHY}

AKRICH, Madeleine; CALLON, Michel; LATOUR, Bruno (2006), Sociologie de la traduction: textes fondateurs, Paris, École de Mines.

BENTHAM, Jeremy (2000), “O Panóptico”, in Tomaz Tadeu Silva (org.), o Panóptico/Jeremy Bentham, Belo Horizonte, Autêntica.

BOTT, Elizabeth (1976), Família e Rede Social, Rio de Janeiro, Francisco Alves.

CALLON, Michel (2003), “Quel espace publique pour la démocratie technique ?”, in Daniel Cefaï e Dominique Pasquier (orgs.), Les Sens du public : publics politiques, publics médiatiques, Paris , CURAPP/PUF, 197-221.

CAMERON, Heather (2004), “CCTV and (In)dividuation”, in Surveillance \& Society (CCTV Special), 2(2/3), 136-144, disponível em: <http://www.surveillance-and-society.org/articles2(2)/ individuation.pdf> (acessado em 21/12/2011).

CARDOSO, Bruno V. (2010), Todos os Olhos: Videovigilâncias, videovoyeurismos e (re)produção imagética na tecnologia digital, Tese de Doutoramento em Ciências Humanas, Universidade Federal do Rio de Janeiro, p. 338.

DELEUZE, Gilles (2010), Conversações, São Paulo, Editora 34.

FOUCAULT, Michel (2003), Vigiar e Punir: Nascimento da prisão, Petrópolis, Vozes.

FYFE, Nicholas, BANNISTER, Jon (1996), "City watching: Closed circuit television surveillance in public spaces”, Area 28(1), 37-46, documento disponível em: <http://www.jstor.org/ pss/20003625> (acessado em 21/12/2011).

GILL, Martin; SPRIGGS, Angela (2005), "Assessing the impact of CCTV, Home Office Research Study 292", documento disponível em: <http://www.homeoffice.gov.uk/rds/pdfs05/hors292. pdf> (acessado em 21/12/2011).

HEILMANN, Éric (2007), “Surveiller (à distance) et prévenir. Une nouvelle économie de la visibilité”, In: Questions de communication, 11, documento disponível em : <http://cat.inist.fr/? aMo dele=afficheN\&cpsidt=21947496> (acessado em 21/12/2011).

HEILMANN, Éric; MORNET, Marie-Noëlle (2001), “L’impact de la vidéosurveillance sur les désordres urbains : le cas de Grande-Bretagne ”, Les Cahiers de la sécurité intérieure, 46, 4e 
trimestre, disponível em: <http://halshs.archives-ouvertes.fr/docs/00/12/55/70/PDF/ArtIhesiEH-2001.pdf> (acessado em 21/12/2011).

HEMPEL, L.; TÖPFER, E (2002), “Urban eye: Inception report to the European Commission, $5^{\text {th }}$ Framework Program", Technical University of Berlin, document disponível em: <http:// www.urbaneye.net/results/ue_wp1.pdf> (acessado em 21/12/2011).

KEVAL, Ina; SASSE, Angela (2006), "Man or a gorilla? Performance issues with CCTV technology in security control rooms", Trabalho apresentado no 16th World Congress on Ergonomics Conference, International Ergonomics Association, Maastrich, Holanda, document disponível em: <http://hornbeam.cs.ucl.ac.uk/hcs/publications/IEA2006_Keval.pdf> (acessado em 21/12/2011).

KOSKELA, Hille (2003), “Cam era - The contemporary urban Panopticon”, Surveillance \& Society, 1(3), 292-313, documento disponível em: <http://www.surveillance-and-society.org/ articles1(3)/ camera.pdf> (acessado em 21/12/2011).

KOSKELA, Hille (2004), "Webcams, TV shows and mobile phones: Empowering exhibitionism", Surveillance \& Society 2 (2/3): 199-215, documento disponível em <http://www.surveillance- and-society.org/articles2(2)/webcams.pdf> (acessado em 21/12/2011).

LATOUR, Bruno (1994), “On technical mediation”, Common Knowledge, Fall 1994, V3, N2, pp. 29-64.

LATOUR, Bruno (2005), Jamais Fomos Modernos: Ensaios de antropologia simétrica, São Paulo, Editora 34

LATOUR, Bruno (2007), Changer de monde, refaire de la sociologie. Paris, La Découverte.

LAW, John, MOL, Annemarie (2002), “Complexities: An introduction”, in Complexities: Social studies of knowledge practices, Durham, Duke University Press.

LE GOFF, Tanguy; FONTENEAU, Mathile (2008), “Vidéosurveillance et espaces publics : État des lieux des évaluations menées en Franceet à l'étranger”, Institut d'Aménagement et d'Urbanisme d'île-de-France, Étude n.․ 20.08.02, documento disponível em: <http://www.iau-idf.fr/fileadmin/ Etudes/etude_534/Synthese_video_esp_public.pdf> (acessado em 21/12/2011).

LIANOS, Michalis (2001), Le Nouveau contrôle social. Toile institutionelle, normativité et lien social, Paris, L'Harmattan.

LIANOS, Michalis (2003), "Le contrôle social après Foucault", Surveillance \& Society 1(3), 431-448, documento disponível em: <http://www.surveillance-and-society.org/articles1(3)/ ApresFoucault.pdf> (acessado em 21/12/2011).

LORANT, A. C. (1995), “La vidéosurveillance et la loi du 21 janvier 1995 sur la sécurité”, Droit de l'informatique et des télécoms, n.․ 4, 9-17, documento disponível em: <http://cat.inist.fr/? aModele $=$ afficheN\&cpsidt $=2489310>($ acessado em 21/12/2011).

LYON, David (1993), “An electronic panopticon? A sociological critique of surveillance theory”, in Sociological Review, 41(4), 653-78.

LYON, David (1994), The Eletronic Eye: The rise of surveillance society, Minneapolis; University of Minnesota Press.

LYON, David (2001), Surveillance Society: Monitoring everyday life. Buckingham: Open University Press.

McCAHILL, Michael; NORRIS, Clive; WOOD, David (2004), "The growth of CCTV: A global perspective on the international diffusion of video surveillance in publicly accessible space", 
Surveillance \& Society 2(2/3), 110-135, documento disponível em: <http://www.surveillance-andsociety.org/articles2(2)/editorial.pdf> (acessado em 21/12/2011).

MITCHELL, J. Clyde (1969), “The concept and use of social networks”, Social Networks in Urban Situations, Manchester, Manchester University Press.

MOLNAR, L. (2003), “Information society as surveillance society, CCTV in Hungary”, in Information Society as Surveillance Society edited by L. Molnar, Budapest, Arisztotelesz Press.

NORRIS, Clive (2002), "From personal to digital: CCTV, the Panopticon, and the technological mediation of suspicion and social control". In Lyon, David (org.) Surveillance as Social Sorting: Privacy, risk and digital discrimination. London: Routledge.

NORRIS, Clive; ARMSTRONG, Gary (1999), The Maximun Surveillance Society: The rise of CCTV. Oxford; Berg.

ORWELL, George (1979), 1984, São Paulo, Editora Nacional.

REEVE, Alan (1998), "The panopticisation of shopping: CCTV and leisure consumption", NORRIS, Clive; MORAN, J.; ARMSTRONG, Gary (orgs.), Surveillance, Closed Circuit Television and Social Control, Aldershot, Ashgate.

SEWELL, Graham; BARKER, James (2001), "Neither good, nor bad, but dangerous: Surveillance as an ethical paradox", Ethics and Information Technology, 3, 183-196, documento disponível em: <http://www.springerlink.com/content/j8h045k51776m184/> (acessado em 21/12/2011).

SHARPE, Sybil (1989), Electronically Recorded Evidence: A guide to the use of tape and video recordings in criminal proceedings, London, Fourmat Publishing.

SMITH, Gavin J. D. (2004), "Behind the screens: Examining constructions of deviance and informal practices among CCTV control room operators in the UK", Surveillance \& Society, 2 (2/3), documento disponível em: <http://www.surveillance-and-society.org/articles2(2)/screens. pdf> (acessado em 21/12/2011).

SMITH, Gavin J. D. (2007), “exploring relations between watchers and watched in control(led) systems: Strategies and tactics", Surveillance \& Society, 4 (3), documento disponível em: <http:// www.surveillance-and-society.org/articles4(3)/watchers.pdf> (acessado em 21/12/2011).

TAYLOR, Nick (2002), "State surveillance and the right to privacy", Surveillance and Society, 1(1): 6-85, documento disponível em: <http://www.surveillance-and-society.org/articles1/statesurv. pdf> (acessado em 21/12/2011).

WALTON, Greg (2001), “China's golden shield: Corporations and the development of surveillance technology in the People's Republic of China", International Centre for Human Rights and Democratic Development, documento disponível em: <http://www.ichrdd.ca/english/commdoc/ publications/goldenShieldEng.html> (acessado em 21/12/2011).

WELSH, Brandon; FARRINGTON, David (2004), "Surveillance for Crime prevention in public space: Results and police choices in Britain and America", Criminology and Public Policy, 3(3), documento disponível em: <http://onlinelibrary.wiley.com/doi/10.1111/j.1745-9133.2004. tb00058.x/abstract> (acessado em 21/12/2011).

WHITAKER, Reg (1999), The End of Privacy: How total surveillance is becoming a reality, New York, The New Press. 


\section{NOTES}

1. Por exemplo, Lyon (1993, 1994, 2001), Norris e Armstrong (1999), Norris (2002).

2. Vale lembrar que críticas semelhantes também aparecem no trabalho de alguns autores sobre o tema, como Smith (2004, 2007), Cameron (2004), Koskella $(2003,2004)$ ou Keval e Sasse (2006).

3. Para a discussão do conceito de complexidade utilizado aqui, ver Law e Mol (2002).

4. Para o conceito de tradução utilizado aqui, ver Akrich, Callon e Latour (2006).

5. Trato aqui de purificação e hibridismo apoiado nas idéias de Latour (2005).

6. Principal estação ferroviária da cidade do Rio de Janeiro. Na torre da estação, funciona a Secretaria Estadual de Segurança Pública.

7. Era, na verdade, tenente-coronel da Polícia Militar, mas por (in)formalismos da caserna, no falar corriqueiro diz-se apenas "coronel".

8. Gíria para delator.

9. Deve-se notar o fato de Copacabana ser uma das principais áreas turísticas da cidade, concentrando também o maior volume de serviços de hotelaria.

10. O tamanho, a densidade demográfica e as características das redes sociais também criam especificidades em cada contexto.

11. Ver Lorant (1995).

12. http://www.cnil.fr/ (acessado em 21/12/2011).

13. Grifos no original.

14. Chamo de sobredeterminação técnica (Cardoso, 2010) a premissa de que um sistema de videovigilância seria constituído principalmente por câmeras, computadores e a estrutura material que estes precisam para operar, enquanto o olhar, a percepção e a comunicação humanas ocupariam um papel secundário, pouco importante. Desse modo, o investimento em mão de obra é posto sempre em segundo plano.

15. As relações multiplex indicam sobreposição de papéis (ligações entre mesmos indivíduos se dariam em múltiplos planos - família, amizade, vizinhança, trabalho, etc. -, constituindo-se redes sociais mais estreitas), enquanto nas relações uniplex, a ligação entre os diferentes indivíduos dentro da rede social (social network) se dá apenas através de um foco de interação (Mitchell, 1969).

16. Como contraponto ao processo de assujeitamento descrito por Foucault (2003), Lianos afirma que o contexto sociotécnico contemporâneo promoveria um desassujeitamento do indivíduo, constituído de forma fragmentada enquanto usuário múltiplo de diversas instituições, com as quais entra em contato através de mediadores não-humanos (catracas, cartões magnéticos, senhas...), sempre no interior de um espaço-tempo específico (físico ou virtual) de atuação e sob responsabilidade institucional. Esse novo controle não permitiria a negociação entre sujeitos, aplicando diretamente sua lógica binária, cujas respostas possíveis se resumem a autorizado e recusado. A decorrente limitação da intersubjetividade implica uma modificação na própria elaboração das normas - que, assim como a difusão das mesmas, ocorre majoritariamente em contextos de interação com o outro -, cada vez mais formalizadas e destacadas dos valores internalizados que as sustentavam. Surge então uma normalidade formal e hiper-regular em que é mais importante "parecer normal" do que "ser normal". É o inverso da sociedade disciplinar, onde a recriação dos indivíduos era parte fundamental do processo de normalização. São notáveis as semelhanças com a perspectiva da "sociedade $d$ controle", esboçada por Deleuze (2010), em substituição à sociedade disciplinar descrita por Foucault.

17. Forma coloquial de se dizer "muito bem".

18. Entre 5 e 6,13 bilhões de euros. Heilmann (2007: 313) lembra ainda que "segundo os profissionais, para cada 10000 euros investidos na instalação de uma câmera, 3000 a 5000 euros 
devem ser mobilizados cada ano para assegurar a sua exploração (salário dos operadores, manutenção, etc.)".

19. Aproximadamente 312 milhões de euros. Vale lembrar que o sistema britânico funciona com parcerias co-financiadas entre poder público e iniciativa privada.

20. Em especial o computador, mas também as câmeras, a rede, o modem, etc.

21. A capacidade preventiva do sistema de videovigilância é marcada por uma característica frequentemente imputada ao trabalho policial no Rio de Janeiro como um todo (ver, por exemplo, Misse, 1999): o processo de suspeição, central para o trabalho preventivo, depende fundamentalmente de velhos estereótipos físicos e sociais (negros - em especial se jovens e do sexo masculino -, moradores de rua, menores de rua, catadores de material reciclável, etc.). A observação preventiva, orientada pelo que os operadores chamavam de "olhar maldoso" (como sinônimo de malicioso), recaía inescapavelmente sobre indivíduos enquadráveis nessas categorias.

\section{ABSTRACTS}

O artigo discute, através de reflexões oriundas de pesquis etnográfica realizada junto a operadores de câmeras de vigilância do Rio de Janeiro, e da comparação com outros contextos e abordagens metodológicas sobre o tema, as possibilidades e desafios do estudo de atividades e identidades profissionais que emergem da aplicação prática de novas tecnologias. Os vigilantes eletrônicos são tomados como agenciamentos sociotécnicos, híbridos de humanos e objetos técnicos cuja existência se limita ao ambiente e horário de trabalho e cuja análise revela aspectos bastante diferentes e problemáticos em relação aos discursos, imaginários e análises que tratam da videovigilância.

This article discusses, based on reflections arising from an ethnographic study of surveillance camera operators in Rio de Janeiro and a comparison with other contexts and methodological approaches to the subject, the possibilities and challenges offered by the study of professional activities and identities emerging from the practical application of new technologies. Electronic surveillants are considered to be sociotechnical agencements, hybrids of humans and technical objects whose existence is limited to the workplace and to work hours. Analysis of these agencements reveals that there are a number of quite varied, problematic issues concerning video surveillance discourse and imaginary, as well as analyses of this form of surveillance.

Cet article débat, à travers des réflexions survenues de la recherche ethnographique menée auprès des opérateurs de caméras de surveillance à Rio de Janeiro, et de la comparaison avec d'autres contextes et approches méthodologiques à propos du sujet, les possibilités et les défis de la recherche sur les activités et les identités professionnelles qui émergent de l'application pratique des nouvelles technologies. Les surveillants électroniques sont considérés comme des agencements sociotechniques, des hybridizations entre humains et objets techniques dont l'existence est limitée à l'environnement et à la période de travail, dont l'analyse révèle des aspects très diverses et problématiques en ce qui concerne les discours, l'imaginaire etlıanalyse portant sur la vidéosurveillance. 
INDEX

Palavras-chave: videovigilância, tecnologia, metodologia, relações sociotécnicas Mots-clés: vidéosurveillance, technologie, méthodologie, rapports sociotechniques

Keywords: video surveillance, technology, methodology, sociotechnical relations

\section{AUTHOR}

\section{BRUNO DE VASCONCELOS CARDOSO}

Doutor em Ciências Humanas (IFCS - Universidade Federal do Rio de Janeiro); Professor Adjunto de Sociologia (Universidade Federal do Rio de Janeiro), brunovcardoso@hotmail.com. 